\title{
Çok Ölçütlü Karar Verme Yöntemleri ile Ekokardiyografi Cihazı Seçiminin Yapılması
}

\section{Echocardiography Device Selection with Multicriteria Decision Making Methods}

\author{
Şeyma CIHAN, ${ }^{\mathrm{a}}$ Enes AYAN, ${ }^{\mathrm{b}}$ Tamer EREN ${ }^{\mathrm{c}}$,Taner TOPAL, ${ }^{\mathrm{d}}$ Erdem Kamil YILDIRIM $^{\mathrm{e}}$
}

ÖZET Amaç: Medikal cihazlar hastanelerde en çok bütçe ayrılan kalemlerdendir. Bu nedenle medikal cihaz alım kararı kritik kararlardan biridir. Bu çalışmada, bir devlet hastanesinde Kardiyoloji Servisine alınması planlanan ekokardiyografi cihazı seçim problemi ele alınmıştır. Gereç ve Yöntem: Ekokardiyografi cihazı seçimini etkileyen kriterler ve mevcut alternatif cihazlar konuyla ilgili literatür taranarak ve kardiyoloji alanında uzman üç hekimin görüşleri alınarak belirlenmiştir. Seçim kriterleri belirlendikten sonra Analitik Hiyerarşi Süreci (AHP) yöntemi ile kriterler ağırlıklandırılmış ve İdeal Çözüme Dayalı Sıralama Tekniği (TOPSIS) yöntemi ile alternatifler sıralanarak en iyi alternatif belirlenmiştir. Bulgular: Ekokardiyografi cihazının seçim problemi için belirlenen alternatiflerin öncelikleri AHP yöntemine göre, B cihazı için \%48, ikinci sırada yer alan A cihazı için \%29, C cihazı için ise \%23 olarak bulunmuştur. TOPSIS yöntemi ile İdeal Uzaklık $\left(\mathrm{S}_{\mathrm{i}}^{*}\right)$, Negatif İdeal Uzaklık $\left(\mathrm{S}_{\mathrm{i}}^{-}\right)$ve her bir karar noktasının ideal çözüme göreli yakınlık $\left(\mathrm{C}_{\mathrm{i}}^{*}\right)$ değerleri $\mathrm{B}$ cihazı için sırasıyla $0,0.124287$ ve 1 olarak bulunmuştur. Sonuç: AHP ve TOPSIS yöntemine göre B cihazı birinci alternatif olarak öne çıkmıştır.

Anahtar kelimeler: AHP, çok ölçütlü karar verme, medikal cihaz seçimi, TOPSIS

\begin{abstract}
Purpose: Medical devices are the most budgeted items in hospitals. For this reason, the decision to buy a medical device is one of the critical decisions. In this study, the selection problem of echocardiography device planned to be taken to a cardiology department in a public hospital was discussed. Methods: Criteria affecting echocardiography device selection and available alternative devices were determined by reviewing the relevant literature and taking the opinions of three physicians specializing in cardiology. After the selection criteria were determined, the criteria were weighted by the Analytic Hierarchy Process (AHP) method and the best alternative was determined by sorting the alternatives by TOPSIS (Technique for Order Preference by Similarity to Ideal Solution) method. Results: The priorities of the alternatives determined for the selection problem of the echocardiography device were found to be $\% 48$ for B, \%29 for A, and \%23 for C, according to the AHP method. With the TOPSIS method, the ideal distance ( $\mathrm{Si}$ *), negative ideal distance (Si-) and the ideal solution relative (Ci *) values of each decision point were found to be $0,0.124287$ and 1 for B, respectively. Conclusion: According to the method of AHP and TOPSIS, device B is the first alternative.
\end{abstract}

Key words: AHP, medical machine selection, multicriteria decision making, TOPSIS

\section{GíRiş}

Günümüzde hastanelerin sağl1k hizmeti verebilmek için medikal teknolojiye olan bağımlılıkları giderek artmaktadır. Sağlık kuruluşlarında hastalar için yüksek kalitede hizmetin sağlanmas1, alanında doğru eğitim almış ve yeterli becerilerle donatılmış uzman personelin varlığıyla mümkündür. Ancak, söz konusu yüksek standartlara ulaşmak ve devam ettirmek için kişisel bilgi ve beceri yeterli değildir. Bunun için uygun alt yapı ve donanım da gerekmektedir. Bu donanım içinde yer alan yenilikçi medikal cihazlar, tanı, tedavi ve rehabilitasyon alanlarında verilen sağlık hizmetinin sonuçlarını olumlu bir şekilde etkilemektedir. ${ }^{1}$ Medikal teknolojilerin temini sağlık harcamaları içinde en önemli gider kalemlerinden biridir. ${ }^{2}$ Dünya sağlık örgütünün 2010 raporuna göre diğer bütün gider kalemleri arasında sağlık bakım sistemi giderleri gelişmekte olan ülke ekonomileri için büyük yük oluşturmaktadır. ${ }^{3}$ Medikal ekipman seçim kararı, hizmet verilen hasta grubunun sağl1k bakımı ve daha sonrasında da yaşam kalitesi üzerindeki önemli etkilerinden dolayı kritik öneme sahiptir. ${ }^{2}$

Medikal cihaz seçme kurum ve kuruluş için zaman alıcı ve ileri düzeyde bilgi ve deneyim gerektiren problemli kritik bir süreçtir. Makine-ekipman seçimi için standart bir katalog sisteminin olmaması, çok sayıda kriterin değerlendirilmesi ve yeni bir ekipmanın teknolojik gelişmelerle birlikte tanıtılması, problemi daha da komplike bir hale

Geliş Tarihi/Received: 15-06-2016 / Kabul Tarihi/Accepted: 11-12-2016

aArş. Gör. Kırıkkale Üniversitesi Mühendislik Fakültesi Bilgisayar Mühendisliği Bölümü cihanseyma@gmail.com,

b Arş. Gör. Kırıkkale Üniversitesi Mühendislik Fakültesi Bilgisayar Mühendisliği Bölümü enesayan@kku.edu.tr,

c Doç. Dr. Kırıkkale Üniversitesi Mühendislik Fakültesi Endüstri Mühendisliği Bölümü tamereren@gmail.com,

d Yrd. Doç. Dr. Kırıkkale Üniversitesi Mühendislik Fakültesi Bilgisayar Mühendisliği Bölümü ttopal@kku.edu.tr,

e Prof. Dr. Kırıkkale Üniversitesi Mühendislik Fakültesi Bilgisayar Mühendisliği Bölümü ekyildirim@gmail.com, Sorumlu yazar /correspondence: Tamer Eren 
getirebilmektedir. Uygun ve etkili bir değerlendirme için, karar vericilerin çok fazla miktarda veriyi analiz etmesi ve birçok faktörü göz önünde bulundurması gerekmektedir. ${ }^{4}$ Ayrıca, uygun olmayan ekipman seçimi bir sisteminin üretkenliğini ve toplam performansını negatif yönde etkileyeceğinden sistemler için oldukça önemli bir eylemdir. ${ }^{5}$ Gerektiğinden daha nitelikli ekipman seçimi ise şirketin nakit akışını aksatabilir, ayrıca atıl ekipman ve aşırı stok gibi problemlere yol açabilir. ${ }^{6}$ Ele alınan problemlerde ulaşılmak istenen hedefin birçok parametre tarafindan belirlendiği ve değerlendirilecek alternatiflerin her birinin kendine has avantajları bulunmaktadır. $\mathrm{Bu}$ sebeple çok ölçütlü karar verme problemi ortaya çıkmakta ve karar verme işi oldukça güçleşmektedir. ${ }^{7}$ Kararlar üzerine etki eden tüm kriterlerin değerlendirilmesi ve analizi amacıyla çok ölçütlü karar verme yöntemleri geliştirilmeye başlanmıştır. ${ }^{8}$ Çok ölçütlü karar verme yöntemleri, elde ki mevcut alternatifleri deterministik kriter değerlerine göre inceleyerek, en iyi uzlaşıcı çözüme ulaşır.

Literatürde çok ölçütlü karar verme yöntemlerinin makine seçim problemine uygulanması ile ilgili çok sayıda çalışma bulunmaktadır. Chatburn ve Primiano ${ }^{9}$ yaptıkları çalışmada yoğun bakım ünitesine ventilatör alımı için çeşitli karar verici mekanizmaların bir araya getirildiği bir model oluşturmuşlardır. Çalışmada, karar verme sürecindeki önemli kriterler tanımlanmıştır. Arslan ve $a r k^{4}$, çalışmalarında makine ekipman seçimi sırasında yaşanan problemleri tanımlamışlar ve kriterleri belirleyerek çok ölçütlü bir karar verme modeli geliştirmişlerdir. Çimren ve $\operatorname{ark}^{10}$, yaptıkları çalışmada Analitik Hiyerarşi Süreci (Analytic Hierarchy Process -AHP) yöntemini kullanarak makine seçim problemi için bir karar destek sistemi yazılımı geliştirmişlerdir. Seçim sürecinde makine özellikleriyle ilgili kalitatif kriterler belirlenmiştir. Kaya ve $\mathrm{ark}^{8}$, insan yarg1 ve değerlendirmelerini de içeren çok kriterli karar verme probleminin uygulanmasını ele almışlardır. Bu süreçte bulanık İdeal Çözüme Dayalı Sıralama Tekniği (Technique for Order Preference by Similarity to Ideal Solution-TOPSIS) yöntemi kullanılmış ve bir işletmeye alınacak uygun Bilgisayar Sayımlı Yönetim (Computer Numerical Control-CNC) cihazı seçim problemine uygulanmıştır. Dağdeviren ${ }^{5}$, AHP ve Tercih Sıralamas1 Zenginleştirme Değerlendirmelerinin Organizasyonu Metodu
(The Preference Ranking Organization Method for Enrichment Evaluation-PROMETHEE) yöntemlerini birlikte kullanarak bir ekipman seçim problemini ele almıştır. Balaji ve ark ${ }^{11}$, Hindistan'da otomotiv sektöründe faaliyet gösteren bir firmanın CNC makinası seçim sürecine destek olmak için Gerçeği Tercüme Eden Eleme ve Seçim (The Elimination and Choice Translating Reality-ELECTRE) yöntemini kullanarak bir yaklaşım geliştirmişlerdir. Ayrıca verilen kararın güvenilirliğini test etmek için duyarlılık analizi de yapmışlardır. Yılmaz ve Dağdeviren ${ }^{6}$, çalışmalarında, bir işletmenin kaynak makinesi seçimi problemini, çok kriterli bir karar verme problemi temelinde incelemişlerdir. Bazzazi ve $\mathrm{ark}^{12}$, çalışmalarında maden ocağı açma makine seçimi problemini ele alarak, AHP yöntemi ve Çok Kriterli Optimizasyon ve Uzlaşı Çözüm (Vise Kriterijumska Optimizacija I Kopmromisno Resenje-VIKOR) yöntemi uygulamışlardır. Özgen ve ark ${ }^{13}$, makine seçim problemi ile ilgili yaptıkları çalışmada, bulanık AHP-PROMETHEE yaklaşımı ile İstanbul'da faaliyet gösteren bir firmanın presleme makinası seçim problemini ele almışlar ve çıkan sonuçları bulanık AHP-TOPSIS yöntemiyle karşılaştırmışlardır. Çalışkan ve $\operatorname{ark}^{14}$, çalışmalarında 19 adet alternatif kesici takım malzemesi ve 10 adet seçim kriterinden oluşan bir karar matrisini ele alarak, kesici takım malzemesi seçimi problemini çözmek amacıyla TOPSIS metodunu uygulamışlardır. Perçin ${ }^{15}$, çalışmasında makine-teçhizat seçimi için bulanık çok ölçütlü karar verme yöntemlerinden AHP ve TOPSIS yöntemlerini kullanmışlardır. Literatür taramas1 ve uzman görüşleri doğrultusunda CNC tezgâhlarının seçimini etkileyen karar kriterlerini belirlemiştir. Taha ve Rostam ${ }^{16}$, CNC makinesi seçimi için AHPPROMETHEE yöntemlerini kullanmışlardır. Ertuğrul ve Özçil ${ }^{17}$ klima seçim kararını etkileyen faktörleri belirlemek ve tercih siralama önerisi sunmak amacıyla yaptıkları çalışmada, TOPSIS ve VIKOR yöntemlerini kullanılmışlardır. Özdağoğlu ${ }^{18}$ çalışmasında üretim faaliyetleri için gereken CNC torna tezgâhının seçiminde VIKOR ve TOPSIS yöntemlerini kullanarak karar vermişlerdir. Rahimdel ve Ataei ${ }^{19}$ yapmış oldukları çalışmada İran'da Golegohar Demir Madeninde kullanılmak üzere kırıcı seçimi için AHP yöntemini kullanmışlardır. Ivlev ve $\operatorname{ark}^{2}$ yılında yaptıkları bir çalışmada belirsizlik altında medikal cihaz seçiminin desteklenmesi 
amacıyla çok ölçütlü karar analizi ile MR cihazı seçimi için bir karar destek mekanizması geliştirilmişlerdir. Kursunoglu ve Onde ${ }^{20}$ AHP yöntemi kullanarak maden havalandırma sisteminde kullanılmak üzere uygun fan seçim işlemi gerçekleştirmişlerdir. Martelli ve $\mathrm{ark}^{1}$ Fransa'daki üniversite hastanelerinde yenilikçi medikal ekipmanların değerlendirilmesi ile ilgili yaklaşımların saptanması amacıyla yaptıkları çalışmada medikal cihaz alımını etkileyen kriterleri saptamışlardır. Martelli ve $\operatorname{ark}^{21}$ yılında yaptıkları bir çalışmada Fransa'daki üniversite hastanelerinde medikal cihazların seçim sürecinde ele alınan değerlendirme kriterleri belirlenmiştir ve çok ölçütlü karar verme yöntemlerine dayan bir karar destek aracı geliştirmişlerdir. Wu ve $\operatorname{ark}^{22}$ makine seçim problemini incelemişlerdir. CNC seçim probleminin çözümü için bulanık VIKOR yöntemine dayanan iki farklı algoritma geliştirilmiş ve sonuçları karşılaştırılmıştır. Karim ve Karmaker ${ }^{23}$ çalışmalarında AHP ve TOPSIS yöntemini kullanarak makine seçimi için bir karar destek sistemi geliştirmişler ve Bangladeş' te bir firmada uygulama yapmışlardır.

$\mathrm{Bu}$ çalışmada, bir devlet hastanesinin kardiyoloji servisine alınacak ekokardiyografi cihazı seçim problemi çok ölçütlü karar verme yöntemlerinden AHP ve TOPSIS yöntemleri kullanılarak en iyi alternatif belirlenmiştir.

\section{Gereç ve Yöntem}

Kardiyoloji Servisine alınması planlanan ekokardiyografi cihazı seçim problemine, çok ölçütlü karar verme yöntemlerinin uygulanma adımları Şekil 1'de gösterilmişti.

Kardiyoloji Servisinde kullanılan mevcut ekokardiyografi cihazının uzun süredir kullanılıyor olması bazı sorunlara yol açmıştır. Bunlar; daha sık arızalanması, arızalanmalardan kaynaklanan bakım-onarım masraflarını artması, bakım ve onarım için gerekli zamanın ve bekleme süresinin uzaması, mevcut ekokardiografi cihazının eski jenerasyon bir cihaz olması nedeniyle bazı tanı prosedürlerinin yapılabilmesine imkan tanımaması ve geliştirme ve işletim giderlerinin fazla olmasidir.

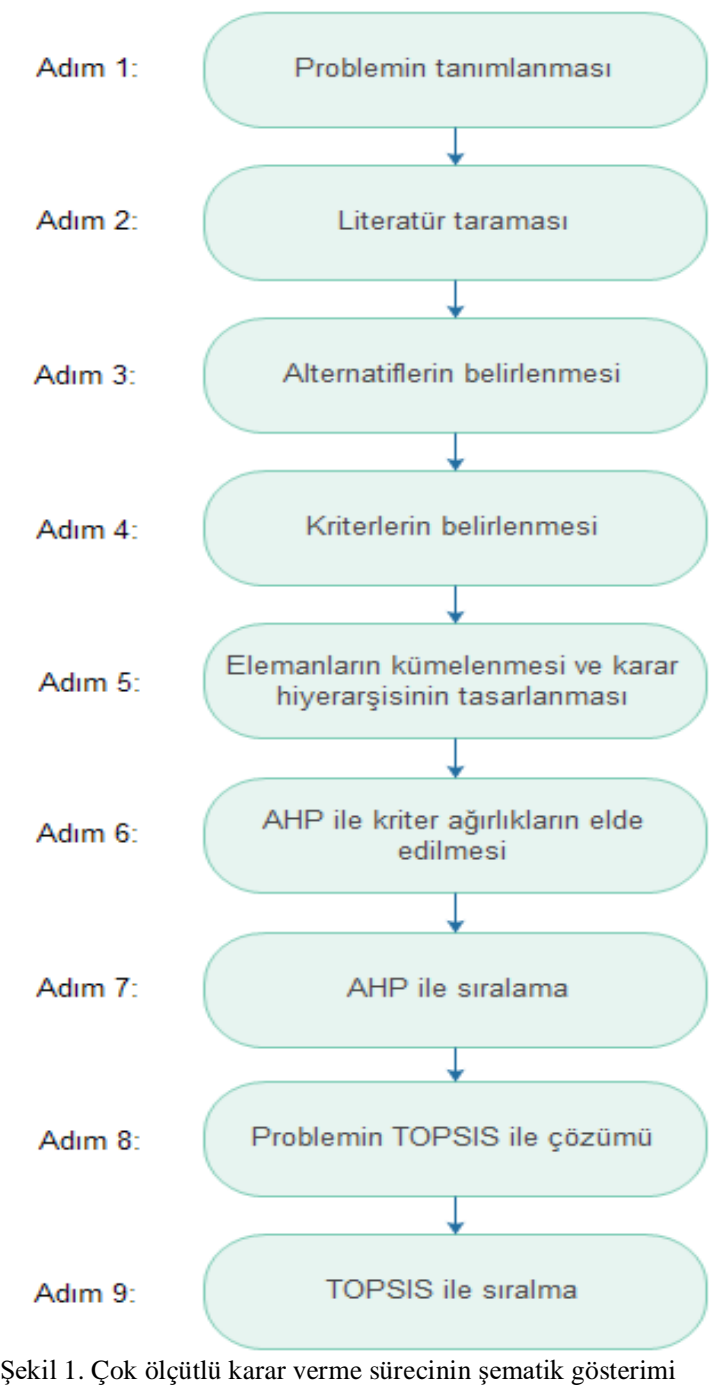

Sonuç olarak Kardiyoloji kliniğine alınması planlanan yeni jenerasyon bir ekokardiyografi cihazı ile aşağıdaki hedeflere ulaşılması beklenmektedir.

- Hasta bakım kalitesinin artırılması

- Uzman personelin yeterli altyap1donanım yoluyla yeterliliklerinin artırılmas1

- Gelecek güncellemeler için uygun teknik altyapı sağlanması

- Bakım onarım maliyetlerinin azalt1lmas1

$\mathrm{Bu}$ çalışmada, hastanenin Kardiyoloji Servisine alınması planlanan ekokardiyografi cihazının seçimi için çok ölçütlü karar verme yöntemlerinden AHP ve TOPSIS yöntemi kullanılmıştır.

\section{Çok Ölçütlü Karar Verme Yöntemleri}

Karar verme, seçenek kümesi içinden en az bir amaç doğrultusunda ve bir ölçüte dayanarak en uygun bir yâda birden fazla seçeneği değerlendirme sürecidir. Doğru kararları 
verebilmek için çok ölçütlü karar verme yöntemleri karşımıza çıkmaktadır. ${ }^{24}$

\section{Analitik Hiyerarşi Prosesi}

AHP, Thomas L. Saaty tarafindan 1980 yilında, karmaşı problemlerin çözümü için geliştirilen, ekonomik sosyal ve teknik alanlardaki birçok problemin çözümü için kullanılan bir yöntemidir. ${ }^{25}$ AHP, öğeleri arasında karmaşık ilişkiler sergileyen karar problemlerinde; öğeler arasında hiyerarşik bir yapıda ilişki barındıran, sezgisel ve mantıksal düşünceyle irdeleyebilen bir yaklaşımdır. ${ }^{26} \mathrm{AHP}$ yönteminin uygulama adımları aşağıdaki adımlardan oluşmaktadır:

Adım 1: Karar probleminin tanımlanması: İlk adımda karar verme problemi net bir şekilde tanımlanmalıdır.

Adım 2: Hiyerarşinin oluşturulması: Amaç, ana ölçütler ve varsa alt ölçütlerden oluşan en az üç seviyede ile temsil edilen bir yapıdır.

Adım 3: İkili karşılaştırma matrislerinin oluşturulması: $\mathrm{Bu}$ matrisler oluşturulurken Saaty tarafindan önerilen 1-9 skalas1 kullanılmaktadır.

Adım 4: Öncelik vektörün (W) hesaplanması: İlgili matristeki her bir öğenin bir diğerine göre önemini gösteren öncelik vektörünün hesaplanması aşamasıdır.

Adım 5: Tutarlılık oranının hesaplanması: Sabit sayılardan meydana gelen ve $n$ değerine göre oluşturulan RI değerleri kullanılarak formüle edilir ve tutarlı11k oran $\leq \leq 0,10$ olması istenir.

\section{TOPSIS Yöntemi}

TOPSIS yöntemi Hwang ve Yoon tarafindan geliştirilen, ideal çözüme en yakın uzaklıkta ve negatif ideal çözüme en uzak bir çözüm belirleyen bir yöntemdir. ${ }^{27}$ TOPSIS yöntemi rasyonelliği ve kolay kavranabilirliği, hesaplamadaki basitliği ve değerlendirme kriterlerinin ağırlıklandırılmasına imkân vermesi gibi avantajları nedeniyle literatürde en çok kullanılan tekniklerden biridir. ${ }^{28}$

TOPSIS yönteminin uygulama adımları aşağıdaki gösterilmektedir:

Adım 1: Karar matrisinin oluşturulması: Oluşturulacak olan karar matrisinde satırlar karar vermede kullanilacak alternatifleri, sütunlar ise belirlenen kriterleri kapsamaktadır. ${ }^{17}$

Adım 2: Standart karar matrisinin oluşturulmas1: Standart karar matrisi A matrisine aşağıdaki formülün uygulanması ile elde edilen bir matristir.

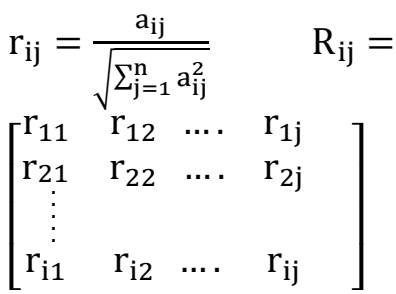

Adım 3: Ağırlıklı standart karar matrisinin oluşturulması: Değerlendirme kriterlerine ilişkin belirlenen ağırlık değerleri $\left(\mathrm{w}_{\mathrm{i}}\right)$ ile standart karar matrisi çarpılarak bulunan matristir.

Adım 4: Pozitif ideal ( $\mathrm{A}^{+}$)ve negatif ideal (A') değerlerinin hesaplanması: Pozitif ideal çözüm seti V matrisindeki ağırlıklandırılmış değerlendirme faktörlerinin yani sütun değerlerinin en büyükleri seçilerek ve Negatif ideal çözüm seti ise, V matrisindeki ağırlıklandırılmış değerlendirme faktörlerinin yani sütun değerlerinin en küçükleri seçilerek oluşturulur.

Adım 5: Ayırım Ölçülerinin Hesaplanması: Her bir alternatife ilişkin karşılaştırma kriteri değerlendirmesinin bulunurken pozitif ve negatif ideal çözüm kümesinden uzaklıkların hesaplanmasidır.

Adım 6: İdeal Çözüme Göreli Yakınlığın Hesaplanması: Burada kullanılan ölçüt, negatif ideal ayırım ölçüsünün toplam ayırım ölçüsü içindeki payıdır. Yakınlık katsayısı değerinin hesaplanmasını gösteren formül aşağıda gösterilmiştir.

$\mathrm{C}_{\mathrm{i}}^{*}=\frac{\mathrm{S}_{\mathrm{i}}^{-}}{\mathrm{S}_{\mathrm{i}}^{-}+\mathrm{S}_{\mathrm{i}}^{*}}$

Formülde gösterilen $\mathrm{C}_{\mathrm{i}}^{*}$ değeri $0 \leq \mathrm{C}_{\mathrm{i}}^{*} \leq 1$ aralığında yer alır ve $\mathrm{C}_{\mathrm{i}}^{*}$ değerinin 1 'e yakın olması ideal çözüme olan yakınlığını ve 0'a yakın olması ideal çözüme olan uzaklığını gösterir. ${ }^{17}$

Ekokardiyografi cihazının seçim problemi için alternatiflerin belirlenmesi amacıyla Türkiye pazarında faaliyet gösteren medikal cihaz firmaları değerlendirilmiştir. Kardiyoloji alanında uzman üç hekimin görüşü 
ve kardiyoloji alanında önemli bir otorite olan Avrupa Kardiyovasküler Görüntüleme Derneğinin standartları ${ }^{29}$ göz önünde bulundurularak aynı segmentte olduğuna karar verilen 3 ayrı medikal cihaz firmasının

ekokardiyografi cihazı firma gizliliğini korumak amaciyla isimleri verilmeyerek A, B, C lternatifi olarak değerlendirilmiştir.

Alternatiflerin belirlenmesinden sonra, literatürde medikal cihaz seçimi ile ilgili yapılmış çalışmalar incelenerek ve kardiyoloji uzmanlarından görüş alınarak kriterler belirlenmiştir. Buna göre maliyet (M), hastaya ilişkin sonuçlar (HİS), medikal cihazın teknik özellikleri (TÖ), satış sonrası servis hizmetleri (SSS), kullanım kolaylığı (KK), güvenlik (G) ve kullanıcı eğitimi (KE) kriterler olarak belirlenmiştir.

Kriterler ve alternatifler arasında hiyerarşik yapının oluşturulmasında, ikili karşılaştırmaların yapılması ve ağırlıkların hesaplamalarda SUPER DECISIONS 1.6.0 yazilımı kullanılmışırı. $^{30}$ Ekokardiyografi cihazının seçim problemi için belirlenen kriter ve alternatifler arasında tanımlanan hiyerarşik yapı oluşturulmuştur (Şekil 2).

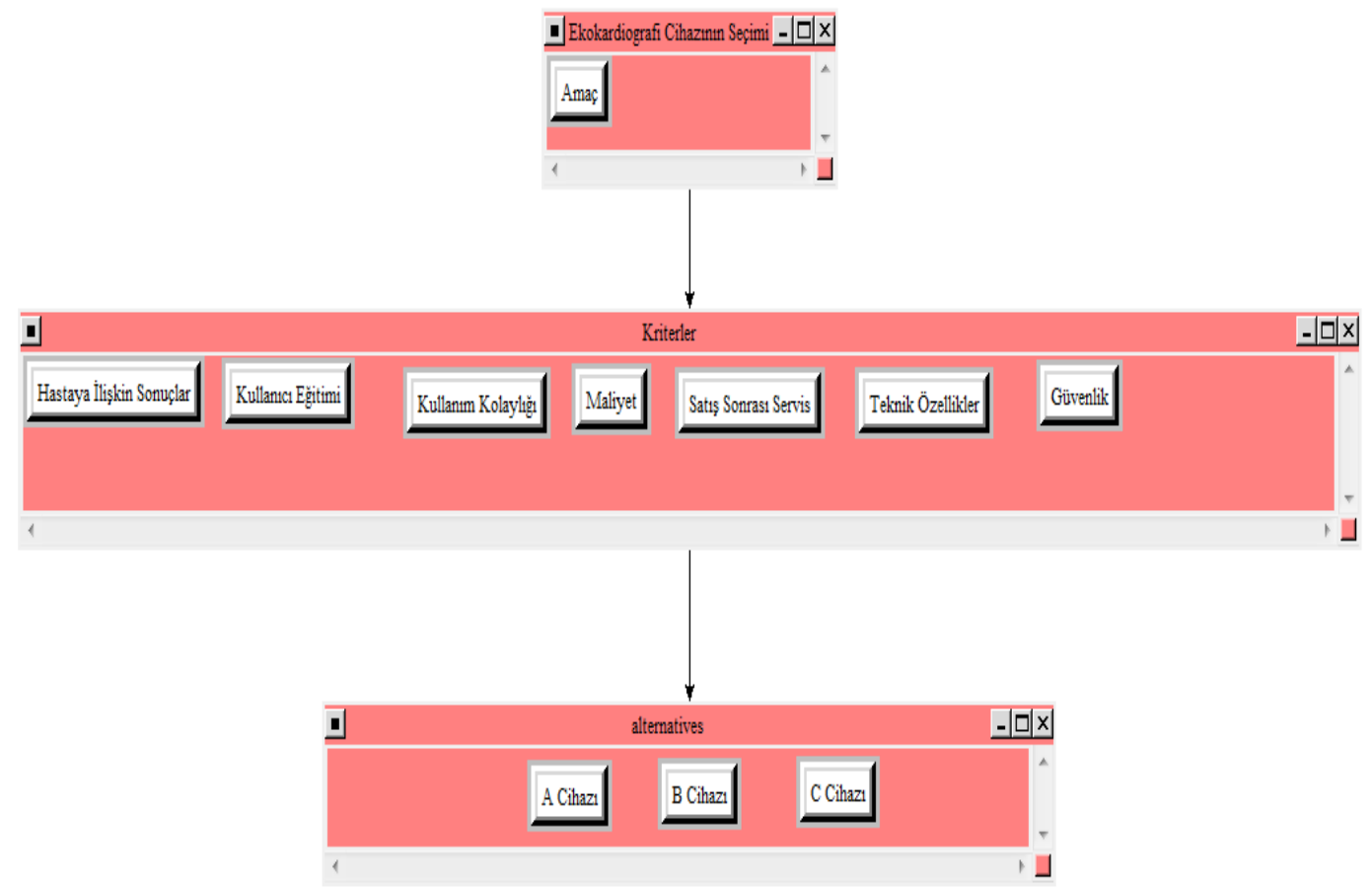

Şekil 2. Çok ölçütlü karar vermede AHP hiyerarşik yapı

Kriterler arasındaki etkileşimi değerlendirmek amacıyla ikili karşılaştırma matrisleri oluşturulmuş ve kriterlerin ağırlıkları belirlenmiştir. Sonrasında, Super decisions paket programiyla AHP yöntemine göre ekokardiyografi cihazının seçim problemi için belirlenen alternatiflerin öncelikleri bulunmuştur. İkinci aşamada, AHP yöntemi ile elde edilen ağırlıklar TOPSIS yönteminde kullanılmış ve belirlenen 3 alternatif arasından en iyi olanın seçimi yapılmıştır.

\section{Bulgular}

AHP yöntemine göre Kriterler arasında etkileşim değerlendirilerek ikili karşılaştırma matrisleri oluşturulmuş ve kriterlerin ağırlıkları belirlenmiştir (Tablo 1).
Tablo 1. AHP sonucunda belirlenen kriterlerin öncelikleri

\begin{tabular}{|l|c|}
\hline Kriterlerin Öncelikleri & $\begin{array}{l}\text { Normalize } \\
\text { Edilmiş } \\
\text { Değerler }\end{array}$ \\
\hline Güvenlik (G) & 0.02172 \\
\hline Hastaya İlişkin Sonuçlar (HİS) & 0.11772 \\
\hline Kullanıcı Eğitimi (KE) & 0.02439 \\
\hline Kullanım Kolaylığı (KK) & 0.08752 \\
\hline Maliyet (M) & 0.24830 \\
\hline Satış Sonrası Servis (SSS) & 0.05671 \\
\hline Teknik Özellikler (TÖ) & 0.44364 \\
\hline
\end{tabular}

Super decisions paket programıla oluşturulan karar matrisi sonucunda kriterlerin ağırlıkları elde edilmiştir. Normalize edilmiş analiz sonuçlarında görüldüğü üzere teknik özellikler kriteri en fazla ağırlı̆̆a sahiptir \%44. Teknik 
özellikler kriterini maliyet ve hastaya ilişkin sonuçlar kriterleri izlemektedir \%12. Ayrıca, ekokardiyografi cihazının seçim problemi için belirlenen alternatiflerin öncelikleri bulunmuştur (Şekil 3).

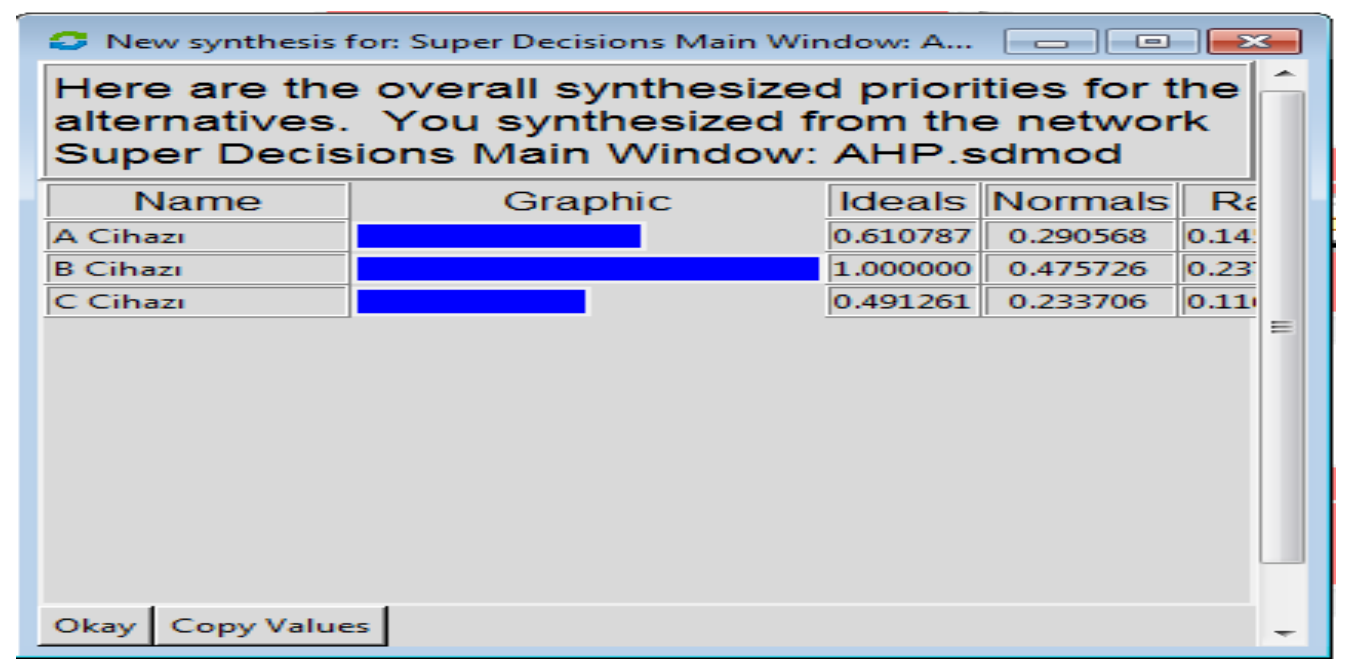

Şekil 3. Super decision programıyla bulunan alternatiflerin öncelikleri

Elde edilen bu sonuçlara göre B marka cihazın öncelik değeri \%48 ile ilk sırada yer almaktadır. A alternatifi ise \%29 normalize değeri ile ikinci sırada yer almıştır. AHP yöntemi ile elde edilen ağırlıklar TOPSIS yönteminde kullanışmış ve belirlenen 3 alternatif arasından en iyi olanın seçimi yapılmıştır. TOPSIS yöntemi ile çözümün ilk aşaması olan karar matrisi oluşturulmuştur (Tablo 2). Karar matrisi oluşturulurken satırlarda üstünlükleri sıralanmak istenen karar noktaları, sütunlarda ise karar vermede kullanılacak değerlendirme faktörleri yer alır. Karar matrisindeki ölçütlere ait puan veya özelliklerin kareleri toplamının karekökü alınarak matris normalize edilir. Daha sonra AHP yönteminde bulunan ağırlıklar kullanılarak ağırlıklı normalize edilmiş karar matrisi hesaplanır (Tablo 3)

Tablo 2. Karar Matrisi

Kriterler

\begin{tabular}{lccccccc} 
Alternatifler & & & & & & & \\
& M & HIS & TÖ & KK & G & KE & SSS \\
A Cihazı & 90 & 8 & 6 & 8 & 7 & 7 & 6 \\
B Cihazı & 10 & 8 & 8 & 9 & 7 & 8 & 7 \\
C Cihazı & 80 & 7 & 5 & 7 & 6 & 7 & 6 \\
\hline
\end{tabular}

Tablo 3. Ağırlıklandırılmış Karar Matrisi

\begin{tabular}{|c|c|c|c|c|c|c|c|}
\hline Ağırlıklar & 0,2483 & 0,11772 & 0,44364 & 0,08752 & 0,02172 & 0,02439 & 0,05671 \\
\hline Alternatifler & M & HIS & TÖ & KK & G & KE & SSS \\
\hline A Cihazı & 0,142769 & 0,070787 & 0,238082 & 0,050268 & 0,013134 & 0,013413 & 0,030932 \\
\hline B Cihazı & 0,158633 & 0,070787 & 0,317442 & 0,056552 & 0,013134 & 0,015330 & 0,036088 \\
\hline C Cihazı & 0,126906 & 0,061938 & 0,198400 & 0,043984 & 0,011257 & 0,013413 & 0,030932 \\
\hline
\end{tabular}

İdeal çözümün oluşturulabilmesi için ağırlıklı standart matristeki değerlendirme faktörlerinin yani sütun değerlerinin en büyükleri seçilmesi gerekmektedir.
Negatif ideal çözüm seti ise, ağırlıklı standart matristeki değerlendirme faktörlerinin yani sütun değerlerinin en küçükleri seçilerek oluşturulur (Tablo 4).

Tablo 4. İdeal ve negatif ideal çözüm

\begin{tabular}{llllllll}
\hline İdeal Çözüm & 0,158633 & 0,070787 & 0,317442 & 0,056552 & 0,013134 & 0,015330 & 0,036088 \\
\hline \multirow{2}{*}{ Negatif İdeal Çözüm } & 0,126906 & 0,061938 & 0,198400 & 0,043984 & 0,011257 & 0,013413 & 0,030932 \\
\hline
\end{tabular}


Her bir karar noktasına ilişkin değerlendirme faktörü değerinin İdeal ve negatif ideal çözümlerden sapmalarının bulunabilmesi için Euclidian Uzaklık Yaklaşımından yararlanılmaktadır. İdeal Uzaklık $\left(\mathrm{S}_{\mathrm{i}}^{*}\right)$ ve
Negatif İdeal Uzakl1k $\left(\mathrm{S}_{\mathrm{i}}^{-}\right)$hesaplandıktan sonra TOPSIS yönteminde son adım olarak her bir karar noktasının ideal çözüme göreli yakınlığı $\left(\mathrm{C}_{\mathrm{i}}^{*}\right)$ ya da diğer bir ifadeyle Pozitif-ideal çözüme olan benzerlikler hesaplanır (Tablo 5).

Tablo 5. Si+, Si- ,Ci değerleri

\begin{tabular}{lllll}
\hline & \multicolumn{1}{c}{ Si $^{+}$} & \multicolumn{1}{c}{ Si- } & \multicolumn{1}{c}{ Ci* $^{*}$} \\
\hline A Cihazı & 0,081360 & 0,044130 & 0,351661 & \\
\hline B Cihazı & 0 & 0,124287 & 1 \\
\hline C Cihazı & 0,124287 & 0 & 0 \\
\hline Sonuç & 1 & B & \\
\hline
\end{tabular}

$\mathrm{Bu}$ sonuçlara göre tercih edilecek ekokardiyografi cihazı ilk sirada yer alan B marka cihazdir.

\section{Tartışma}

Literatürde, makine-ekipman seçimi ile ilgili bir çok yöntem geliştirilmiştir. Ancak makineekipman seçim problemi tipik olarak çeşitli kriterlerin ve bir dizi alternatifin olduğu çok ölçütlü karar verme problemidir ${ }^{31}$. Çok ölçütlü karar verme yöntemleri, elde ki mevcut alternatifleri deterministik kriter değerlerine göre inceleyerek, en iyi uzlaşıcı çözüme ulaştırır ve sonucunda karar verici eldeki mevcut alternatifleri siralayabilir, gruplandırabilir veya aralarından seçim yapabilir ${ }^{32}$. Bu çalışma kapsamında, medikal cihaz seçim problemi çok ölçütlü karar verme problemi olarak ele alınmış ve problemin çözümünde sistematik bir yaklaşım izlenmiştir. Medikal cihaz seçimini etkileyen kriterlerin ağırlıklarının belirlenmesinde AHP yöntemi kullanılmıştır. Çok ölçütlü karar verme yöntemlerinin analizi, AHP yönteminin medikal ekipman seçiminde majör kriterlerin tanımlanması açısından oldukça etkili olduğunu göstermektedir ${ }^{33}$. AHP yöntemi, sağlık bakımı ve medikal karar verme sürecinde; tanılama, hasta katılımı, tedavi, organ transplantasyonu, proje-teknoloji değerlendirme ve seçme, insan kaynakları planlama, sağlık bakımını ve politikalarını değerlendirme gibi birçok alanda kullanılmaktadır. Bununla birlikte, yapılan literatür incelemelerinde AHP yönteminin en fazla proje ve sağl1k teknolojisi değerlendirme ve seçme sürecinde kullanıldığını göstermektedir. AHP yönteminin bu kullanım alanları, yöntemin bir değerlendirme arac1 olarak gücünü göstermektedir ${ }^{34}$.
Yapılan çalışmada, ekokardiyografi cihazı seçimini etkileyen kriterlerden teknik özellikler, maliyet ve hastaya ilişkin sonuçların karar verme sürecinde daha fazla ağırlığa sahip olduğu görülmektedir. Kriter ağırlıkları ile ilgili çalışma bulgularının, literatürde medikal cihaz seçimi ile ilgili çalışmalarla benzerlik gösterdiğ $\mathrm{i}^{2,1,9}$. $\mathrm{Bu}$ sonuçlar, belirlenen kriterlerin farklı medikal cihaz seçim problemlerinde de kullanılabileceğini göstermektedir.

Hastaneler, kaynaklarının önemli bir kısmını yeni medikal cihazların temini için kullanmaktadırlar. Ancak medikal teknolojinin seçim süreci birçok hastanede iyi yönetilmemektedir ${ }^{35}$. Kliniklerde büyük maliyetleri olan hasta bakım ekipmanlarının alımı genellikle kısa süreli deneme süresince kazanılan sübjektif izlenimlere dayanmaktadır. $\mathrm{Bu}$ yaklaşım teknik özellikleri açık olan ve maliyeti birkaç bin doların altında olan ekipmanlar için uygun olabilmektedir. Ancak ileri teknoloji gerektiren yenilikçi medikal ekipmanların durumu diğer ekipmanlardan farklıdır 9 . Bu nedenle, bu çalışma ile oluşturulan kavramsal çerçevenin ve sistematik yaklaşımın, bir çok sağlık kuruluşu için zaman alıcı ve kritik bir süreç olan medikal ekipman seçim sürecinde kullanılabileceği düşünülmektedir. Ayrıca, çok ölçütlü karar verme yöntemlerinin uygun bir şekilde kullanılması ile birlikte, medikal teknoloji ile ilgili uzman kișilerin de sürece dahil edilmesi ile edinilen teknoloji hasta bakımının iyileştirilmesine, maliyet ve risklerin kontrol altına alınmasına katkıda bulunmaktadır ${ }^{36}$. Bu nedenle çalışmada, çok ölçütlü karar verme yöntemleri uygulanırken, medikal teknoloji ile ilgili uzmanlar sürece dahil edilmiştir. 


\section{Sonuç}

$\mathrm{Bu}$ çalışmada, bir devlet hastanesinin Kardiyoloji Servisine alınması planlanan ekokardiyografi cihazı seçim problemi ele alınmıştır. Ekokardiyografi cihazı seçimini etkileyen 7 adet kriter konuyla ilgili literatür taranarak ve kardiyoloji alanında uzman üç hekimin görüşleri alınarak; maliyet, güvenlik, hastaya ilişkin sonuçlar, kullanıcı eğitimi, kullanım kolaylığı, satış sonrası servis ve teknik özellikler olarak belirlenmiştir. Ayrıca, yine uzman hekimin değerlendirmeleri ve Avrupa Kardiyovasküler Görüntüleme Derneği tarafindan belirlenen ekokardiyografi cihazı standartları da göz önünde bulundurularak 3 adet alternatif cihaz; A, B ve C olarak temsili belirlenmiştir. Ekokardiyografi cihazının seçim problemi çok ölçütlü karar verme yöntemlerinden olan; AHP ve TOPSIS yöntemleri ile değerlendirilmiştir.

Değerlendirme sonuçlarına bakıldığında B cihazı birinci alternatif olarak öne çıkmıştır. B ekokardiyografi cihazını sırasıyla A ve $C$ markalı cihazlar izlemiştir.

\section{Kaynaklar}

1. Martelli N, Hansen P, Van Den Brink H, Boudard A, Cordonnier AL, Devaux C, et al. Combining Multi-Criteria Decision Analysis And Mini-Health Technology Assessment: A Funding Decision-Support Tool for Medical Devices in A University Hospital Setting. Journal of Biomedical Informatics 2016; 59: 201-208.

2. Ivlev I, Vacek J, Kneppo P. Multi-Criteria Decision Analysis For Supporting The Selection Of Medical Devices Under Uncertainty. European Journal of Operational Research, 2015; 247(1): 216228.

3. World Health Organization. World Health Report 2010: Health Systems Financing, The Path To Universal Coverage. Geneva, Switzerland Available from http://www.who.int/whr/2010/10_summary en.pdf. Erişim Tarihi: 7.6.2016.

4. Arslan Ç, Catay M, Budak E. A Decision Support System for Machine Tool Selection. Journal of Manufacturing Technology Management 2004; 15(1): 101-109.

5. Dağdeviren $M$. Decision Making in Equipment Selection: An Integrated Approach with AHP and PROMETHEE. Journal of Intelligent Manufacturing 2008; 19(4): 397-406.
6. Yılmaz B, Dağdeviren M. Ekipman Seçimi Probleminde PROMETHEE ve Bulanık PROMETHEE Yöntemlerinin Karşılaştırmalı Analizi. Gazi Üniversitesi Mühendislik-Mimarlık Fakültesi Dergisi 2010; 25(4): 811-826.

7. Santos FA, Garcia R. Decision Process Model To The Health Technology Incorporation. In Engineering in Medicine and Biology Society (EMBC), 2010 Annual International Conference of the IEEE 2010; 414-417.

8. Kaya İ, Kılınç MS, Çevikcan E. Makine Teçhizat Seçim Probleminde Bulanık Karar Verme Süreci. Mühendis ve Makine 2007; 49(576): 8-14.

9. Chatburn RL, Primiano JFP. Decision Analysis For Large Capital Purchases: How To Buy A Ventilator. Respiratory care 2001; 46(10): 1038-1053.

10. Çimren E, Çatay B, Budak E. Development of a Machine Tool Selection System Using AHP. The International Journal of Advanced Manufacturing Technology 2007; 35(3-4): 363-376.

11. Balaji CM, Gurumurthy A, Kodali R. Selection Of A Machine Tool For FMS Using ELECTRE III-A Case Study. IEEE International Conference on Automation Science and Engineering 2009; 171-176.

12. Bazzazi, AA, Osanloo M, Karimi B. Deriving Preference Order of Open Pit Mines Equipment through MADM Methods: Application of Modified VIKOR Method. Expert Systems with Applications 2011; 38(3): 2550-2556.

13. Özgen A, Tuzkaya G, Tuzkaya UR, Özgen D. A Multi-Criteria Decision Making Approach For Machine Tool Selection Problem In A Fuzzy Environment. International Journal of Computational Intelligence Systems 2011; 4(4): 431-445.

14. Çalışkan H, Kurşuncu B, Kurbanoğlu C, Güven ŞY. TOPSIS Metodu Kullanılarak Kesici Takım Malzemesi Seçimi. Makine Teknolojileri Elektronik Dergisi 2012; 9(3): 35-42.

15. Perçin S. Bulanık AHS Ve TOPSIS Yaklaşımının Makine teçhizat Seçimine Uygulanmasi. Çukurova Üniversitesi Sosyal Bilimler Enstitüsü Dergisi 2012; 21(1): 169184.

16. Taha Z, Rostam S. A Hybrid Fuzzy AhpPromethee Decision Support System for Machine Tool Selection in Flexible 
Manufacturing Cell. Journal of Intelligent Manufacturing 2012; 23(6): 2137-2149.

17. Ertuğrul İ, Özçil A. Çok Kriterli Karar Vermede TOPSIS ve VIKOR Yöntemleriyle Klima Seçimi. Çankırı Karatekin Üniversitesi İktisadi ve İdari Bilimler 2014; 4(1): 267-282.

18. Özdağoğlu A. Üretim Faaliyetinde Bulunan İşletmeler İçin CNC Torna Tezgâhı Alternatiflerinin VIKOR ve TOPSIS Yöntemleri İle Karşılaştırılması. Abant İzzet Baysal Üniversitesi Sosyal Bilimler Enstitüsü Dergisi 2014; 14(2): 37-57.

19. Rahimdel MJ, Ataei M. Application of Analytical Hierarchy Process to Selection of Primary Crusher. International Journal of Mining Science and Technology 2014; 24(4): 519-523.

20. Kursunoglu N, Onder M. Selection of An Appropriate Fan For An Underground Coal Mine Using The Analytic Hierarchy Process. Tunnelling And Underground Space Technology 2015; 48: 101-109.

21. Martelli N, Billaux M, Borget I, Pineau J, Prognon, P, Van Den Brink H. Introduction of Innovative Medical Devices at French University Hospitals: An Overview Of Hospital-Based Health Technology Assessment Initiatives. International Journal Of Technology Assessment In Health Care 2015; 31(1-2): 12-18.

22. Wu Z, Ahmad J, Xu J. A Group Decision Making Framework Based On Fuzzy VIKOR Approach For Machine Tool Selection With Linguistic Information. Applied Soft Computing 2016; 42: 314-324.

23. Karim R, Karmaker CL. Machine Selection by AHP and TOPSIS Methods. American Journal of Industrial Engineering 2016; 4(1): 7-13.

24. Dağdeviren M, Eren T. Tedarikçi Firma Seçiminde Analitik Hiyerarşi Prosesi Ve 0-1 Hedef Programlama Yöntemlerinin Kullanılması. Gazi Üniversitesi Mühendislik Mimarlık Fakültesi Dergisi 2001; 16(1-2): 41-52.

25. Saaty TL. The Analytic Hierarchy Process. New York: McGraw-Hill; 1980.

26. Felek S, Yuluğkural Y, Aladağ Z. Mobil İletişim Sektöründe Pazar Paylașımının Tahmininde AHP ve ANP Yöntemlerinin Kıyaslaması. Makine Mühendisleri Odası Endüstri Mühendisleri Dergisi 2007; 18(1): 6-22.
27. Cristóbal JRS. Contractor Selection Using Multicriteria Decision Making Methods. Journal of Construction Engineering and Management 2012; 138(6): 751-758.

28. Çakır S, Perçin S. Çok Kriterli Karar Verme Teknikleriyle Lojistik Firmalarında Performans Ölçümü. Ege Akademik Bakış 2013; 13(4): 449-459.

29. Popescu BA, Stefanidis A, Nihoyannopoulos P, Fox KF, Ray S, Cardim $\mathrm{N}$, et al. Ekokardiyografi Laboratuvarlarının Akreditasyonu İçin Avrupa Kardiyovasküler Görüntüleme Derneği Tarafindan Belirlenmiş Güncel Standartlar Ve İşlemler. Türk Kardiyol Dern Arş - Arch Turk Soc Cardiol 2014; 42(3): 17-31.

30. Super Decisions version 1.6.0 by Creative Decisions Foundation, Pittsburgh, USA, website:www.superdecisions.com. 2016.

31. Ayağ Z, Özdemir RG. A Fuzzy AHP Approach To Evaluating Machine Tool Alternatives. Journal of intelligent manufacturing 2006; 17(2): 179-190.

32. Genç T, Masca M. TOPSIS ve PROMETHEE Yöntemleri ile Elde Edilen Üstünlük Siralamalarının Bir Uygulama Üzerinden Karşılaş̧tırılması. Afyon Kocatepe Üniversitesi IIBFF Dergisi 2013;.15(2): 539566.

33. Ivlev I, Kneppo P, Bartak M. Multicriteria Decision Analysis: A Multifaceted Approach To Medical Equipment Management. Technological and Economic Development of Economy. 2014; 20 (3): 576-589.

34. Liberatore MJ, Nydick RL. The Analytic Hierarchy Process İn Medical And Health Care Decision Making: A Literature Review. European Journal of Operational Research 2008; 189(1): 194-207.

35. David Y, Jahnke EG. Medical Technology Management: From Planning To Application. In Proceedings of the 2005 IEEE engineering in medicine and biology 27th annual conference, Shanghai, China 2005; 186-189.

36. Sloane, EB, Liberatore MJ, Nydick RL, Luo W, Chung QB. Using The Analytic Hierarchy Process As A Clinical Engineering Tool To Facilitate An İterative, Multidisciplinary, Microeconomic Health Technology Assessment. Computers \& Operations Research 2003; 30(10): 14471465. 